\title{
Material Correlates Analysis (MCA): An Innovative way of Examining Questions in Archaeology Using Ethnographic Data - ERRATUM
}

\section{Michael Gantley, Harvey Whitehouse, and Amy Bogaard}

DOI:10.1017/aap.2018.9, Published by Cambridge University Press, 19 July 2018.

The original publication of this article (Gantley et al. 2018) omitted the following text from the Data Availability Statement:

No original data were presented in this paper. The ethnographic data source for this research consisted entirely of the ethnographic reports/accounts available via the electronic Human Relations Area Files (eHRAF) online, cross-cultural ethnographic database of world cultures provided by Yale University, the host of the eHRAF database (http://ehrafworldcultures.yale.edu/ehrafe/). The data used were extracted through targeted searching using both keywords and specific Outline of Cultural Material (OCM) search codes relating to specific cultural information. The eHRAF cultures in our research reflect a defined subset of the sample of 74 groups classified as imagistic or doctrinal by Atkinson and Whitehouse (2011). The archaeological data were gathered through examination of all published and accessible material relating to each site-phase, at the time of the data gathering phase of this research. The doctoral thesis that this article directly relates to is subject to an embargo until September 2019. After this date, it will be fully accessible via the Oxford University Research Archive (ORA) institutional repository for the University of Oxford (https://ora.ox.ac.uk/).

The publisher apologizes for the error.

\section{REFERENCE}

Gantley, Michael, Harvey Whitehouse, and Amy Bogaard

2018 Material Correlates Analysis (MCA): An Innovative way of Examining Questions in Archaeology Using Ethnographic Data. Advances in Archaeological Practice. doi:10.1017/aap.2018.9. 